\title{
Spreadsheet-based modelling of hysteresis-affected curves
}

\author{
Mohammad Zakwan ${ }^{1}$
}

Received: 2 May 2018 / Accepted: 12 June 2018 / Published online: 19 June 2018

(c) The Author(s) 2018

\begin{abstract}
Design, operation and management of water resource projects are influenced by the amount of discharge passing through the stream. Discharge at the gauging site is generally estimated by developing single-valued simple rating curves. However, in case of unsteady flows, hysteresis affect is introduced in the stage discharge relationship and as such single-valued rating curves are no longer valid for such situations. The present paper presents a simple spreadsheet-based optimization approach for modelling the hysteresis-affected discharge rating curves. Generalized reduced gradient (GRG) technique has been reported as a reliable tool for handling optimization problems; therefore, in the present paper, it has been applied to estimate discharge for two sites with hysteresis affect based on Jones formula. Comparison of results shows that discharge estimated by GRG technique is as efficient as genetic algorithm and the goodness-of-fit criteria shows that the rating curves obtained by using Jones formula fit the observed data better than single-valued simple rating curves for both the sites considered in the present study. Application of spreadsheet-based GRG optimization technique could prove very helpful to the hydrometric offices.
\end{abstract}

Keywords GRG $\cdot$ Hysteresis $\cdot$ Optimization $\cdot$ Rating curves $\cdot$ Spreadsheet

\section{Introduction}

Design and operation of hydraulic structures mainly rely on the amount of discharge reaching these structures. Quantification of discharge passing through a river section is of utmost importance in river engineering practices, water management, water distribution systems, design of hydraulic structures and water quality monitoring. Therefore, accurate estimation of streamflow is of utmost importance in water resource engineering. Streamflow estimation is generally accomplished through developing stage-discharge relationship at the gauging site so that measured stage may be converted into discharge as direct measurement of discharge in a river is very costly and time-consuming process. Generally, a single-valued relationship is fitted to the observed data of stage and discharge. The single-valued stage-discharge relationship usually performs well in estimation of discharge in case of steady flow but may lead to inaccurate estimation of discharge if significant unsteadiness is introduced in the

Mohammad Zakwan

zakwancivil@gmail.com

1 Department of Civil Engineering, IIT Roorkee, Roorkee 247667, India flow as in case of flood waves (Herschy 1995; Zakwan et al. 2017a).

When a flood wave propagates through a river corresponding to same stage higher discharges are observed during rising stage than in falling stages resulting in looped rating curves. This affect is popularly known as hysteresis in stage-discharge relationship. Several methods have been proposed by various researchers to account for hysteresis affect in discharge rating curves. However, Jones (1916) formula is the most acceptable approach to account hysteresis affect in rating curves. Fread (1975) Faye and Cherry (1980) also proposed models which could mimic the looped rating curves efficiently, but their scope was limited as application of these models required information on channel slope, Manning roughness coefficient and cross-sectional geometry. Many researchers have commented on the logic behind Jones formula but the logical aspect behind the Jones formula was justified by Perumal and Ranga Raju (1999) by suggesting that the Jones formula is based on approximate convection-diffusion (ACD) equation. Several modifications in the Jones formula has been proposed (Perumal et al. 2004), but the extensive requirement of hydraulic parameters could limit their application (Petersen$\emptyset$ verleir 2006). Petersen- Øverleir (2006) proposed a simple approach based on Jones formula and nonlinear regression 
which requires only stage-discharge data and time of measurement, to model the hysteresis-affected rating curves. PetersenØverleir (2006) successfully applied this approach for various gauging sites affected by hysteresis in USA.

Tawfik et al. (1997) applied a three-layer back propagation artificial neural network (ANN) to model the hysteresisaffected rating curves of two sites Melut and Malakal of river White Nile. Based on the comparative analysis of Boyer's approach, falling and rising approach and ANN modelling, they concluded ANN-based modelling as the most accurate among the three. Analysing the stage-discharge data of 1993 flood for four stations in middle Mississippi Westphal et al. (1999) reported that the rating curves at these sites were affected by hysteresis. They developed single-valued stage-discharge rating curves using power law and seconddegree polynomial and found that these approaches could not satisfactorily mimic the discharge rating curves in case of floods. Jain and Chalisgaonkar (2000) used back propagation feed forward ANN for modelling hypothetical looped rating curves. However, using the same data set as by Jain and Chalisgaonkar (2000), Sudheer and Jain (2003) demonstrated that radial basis function (RBF) neural network are much superior to back propagation neural network in modelling the hysteresis-affected rating curves. Goel and Pal (2011) used support vector machine (SVM) to model the hypothetical looped rating curve by dividing the data set into rising and falling stages. However, training complex ANN periodically is a cumbersome task. Therefore, the present paper proposes a very simple spreadsheet-based optimization approach to model the hysteresis-affected rating curves.

Rating curve: Continuous measurement of discharge is very costly and time consuming; therefore, in majority of the streams, estimation of discharge is generally accomplished by establishing a single-valued relation between stage and discharge which may be presented as

$Q_{n}=K(h-a)^{n}$

$Q_{n}=$ steady state discharge in stream; $h=$ stage height; $a=\mathrm{a}$ constant representing the gauge reading corresponding to zero discharge; $K$ and $n$ are the rating curve constants.

However, the above relationship is incapable of modelling the unsteady flows; therefore, Jones formula is used to incorporate unsteady flow affects which may be presented as

$Q=Q_{n} \sqrt{1+\frac{1}{S C} \frac{\partial h}{\partial t}}$

where $S=$ bottom slope and $C=$ flood wave celerity.

Equation (2) may also be presented as

$Q=K(h-a)^{n} \sqrt{1+x \frac{\partial h}{\partial t}}$

where $x=\frac{1}{\mathrm{SC}}$.

每

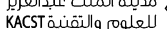

Equation (3) is much similar to the nonlinear regression equation used by Petersen- $\varnothing$ verleir (2006) to model the hysteresis rating curves. In the present paper, Eq. (3) has been used to model the hysteresis-affected rating curves. The four parameters in Eq. (3) were determined by using nonlinear optimization approaches generalized reduced gradient (GRG) and genetic algorithm (GA). Brief description of these approaches is as follows.

\section{GRG technique}

Lasdon et al. (1978) developed GRG optimization code to solve complex nonlinear programming problems. GRG technique is basically a nonlinear extension of simplex method of linear programming that determines the search direction and performs a line search to solve system of nonlinear equations at each step. GRG technique has been found to be one of the most reliable approach to solve highly complex nonlinear programming problems (Lasdon and Smith 1992). Depending on the available storage, GRG technique involves either of the two techniques viz. Quasi-Newton method or Conjugate Gradient method to determine the search direction. However, the Quasi-Newton method is the default choice which maintains an approximation to the Hessian matrix and requires more storage space.

Strong graphical interface and ease in use has attracted the researchers towards the application of spreadsheet to solve engineering problems over the years. Analysis of hydraulic design projects was carried out on spreadsheet by Weiss and Gulliver (2001). GRG technique was applied by Bhattacharjya (2011) to obtain the optimal solution of groundwater flow inverse problem. Che et al. (2014) found GRG solver as reliable as general algebraic modelling system (GAMS) to determine optimal unit hydrographs of watersheds. Muzzammil et al. (2015) applied GRG technique to model the discharge rating curve. Zakwan and Muzzammil (2016) applied GRG technique to model the nonlinear form of Muskingum flood routing equation demonstrating that nonlinear form of Muskingum flood routing equation estimates the outflow more accurately. Zakwan et al. (2016) used GRG technique to estimate the parameters of various infiltration models. Recently, Zakwan et al. (2017b) compared the performance of GRG solver and GA for establishing stage discharge curve in case of steady flow and reported the same result for either optimization technique.

\section{Genetic algorithm}

Genetic algorithm was developed by Holland (1975); however, it became popular after Goldberg (1989). Genetic algorithm is a form of biologically inspired optimization 
technique and comes under the stochastic class of optimization technique. GA is capable of handling wide variety optimization problem with continuous or discontinuous objective functions. Darwin's rule of survival of the fittest was the source of inspiration behind the development of this algorithm (Haupt and Haupt 2004; Pandey et al. 2018). In this algorithm, random population of solutions is generated to start the search and the population evolves through operators based on natural genetic variation and natural selection. In GA at each step, parents are selected from current population based on the selection rules; these parents then combine to generate elite children, crossover children and mutation children. GA differs from other heuristic search algorithms as in this algorithm search is conducted based on population information that consist of a subset of solutions. The population of chromosomes is updated till convergence, or until a specified number of updates are completed.

\section{Data}

Data of two gauging sites downstream of Buford dam in Chattahoochee River, Georgia, USA, has been considered in the present study. The data sets correspond to the flood wave that propagated through these sites on 23 March 1976. On Littles Ferry Bridge, the stage discharge data were available at every 10-min interval, while for Georgia Highway 141 the stage discharge data were available at every 5-min interval. About 25\% data were used for the validation of results for both the sites. The ranges of the stage discharge data for these sites are presented in Table 1.

\section{Analysis, results and discussion}

In the present paper, two data sets affected by hysteresis were considered. The stage-discharge for the two sites was established using simple single-valued relationship as well as the Jones method. The parameters in simple rating curve and Jones method were estimated using spreadsheetbased optimization technique and genetic algorithm. For calibration and validation of results using GRG technique, simple rating curve (Eq. 1) and Jones formula (Eq. 3) were modelled on spreadsheet. The parameters in these equations were estimated by minimizing the sum of square of error (Eq. 4) and are reported in Table 2.

$\mathrm{SSE}=\sum_{i=1}^{N}[X-Y]^{2}$

where $X$ is the observed discharge, and $Y$ is the estimated discharge.

The estimated discharge by the two approaches was assessed quantitatively as well as qualitatively. Quantitative analysis was carried on the following basis

Root mean square $\left(\right.$ RMSE) $=\sqrt{\frac{\sum_{i=1}^{n}(X-Y)^{2}}{N}}$

Correlation coefficient $(r)$

$$
=\frac{N\left(\sum X Y\right)-\left(\sum X\right)\left(\sum Y\right)}{\left.\sqrt{\left(N \left(\sum\left(Y^{2}\right)\right.\right.}-\left(\sum Y\right)^{2}\right)\left(N\left(\sum X\right)-\left(\sum X\right)^{2}\right)}
$$

Modified Index of Agreement (IA) $=\left[1-\frac{\sum_{i=1}^{N}|X-Y|}{\sum_{i=1}^{N}|X-\bar{X}|+|Y-\bar{X}|}\right]$

Table 2 Hysteresis rating curve parameters for two sites by different method

\begin{tabular}{llrlll}
\hline Station & Method & \multicolumn{1}{l}{$K$} & \multicolumn{1}{l}{$a$} & $n$ & \multicolumn{1}{l}{$x$} \\
\hline Littles Ferry Bridge & SRC & 3.55 & 886.14 & 2.74 & - \\
& Jones (GRG) & 2.07 & 885.46 & 2.90 & 816.45 \\
& Jones (GA) & 2.06 & 885.46 & 2.90 & 816.46 \\
Georgia Highway 141 & SRC & 24.91 & 875.29 & 2.34 & - \\
& Jones (GRG) & 98.20 & 876.98 & 1.90 & 628.47 \\
& Jones (GA) & 98.20 & 876.97 & 1.90 & 628.46 \\
\hline
\end{tabular}

Table 1 Statistical characteristics of flood data

\begin{tabular}{lllllc}
\hline Data & Station & Quantity & Max. & Min. & Mean $(\mu)$ \\
\hline Calibration & Littles Ferry Bridge & Discharge $\left(\mathrm{ft}^{3} / \mathrm{s}\right)$ & 7670 & 830 & 3664.56 \\
& & Stage $(\mathrm{ft})$ & 902.26 & 893.56 & 898.16 \\
& \multirow{2}{*}{ Georgia Highway 141 } & Discharge $\left(\mathrm{ft}^{3} / \mathrm{s}\right)$ & 6550 & 1490 & 4140.96 \\
& & Stage $(\mathrm{ft})$ & 885.96 & 881.01 & 883.993 \\
Validation & \multirow{2}{*}{ Littles Ferry Bridge } & Discharge $\left(\mathrm{ft}^{3} / \mathrm{s}\right)$ & 7500 & 1090 & 3836.67 \\
& & Stage $(\mathrm{ft})$ & 902.26 & 894.56 & 898.40 \\
& \multirow{2}{*}{ Georgia Highway 141 } & Discharge $\left(\mathrm{ft}^{3} / \mathrm{s}\right)$ & 6520 & 1490 & 3978.39 \\
& & Stage $(\mathrm{ft})$ & 885.95 & 881.01 & 883.25 \\
\hline
\end{tabular}


Table 3 Performance indices for two sites during calibration

\begin{tabular}{llrll}
\hline Station & Method & RMSE & IA & Correlation \\
\hline Littles Ferry Bridge & SRC & 648.95 & 0.86 & 0.96 \\
& Jones (GRG) & 144.25 & 0.97 & 0.99 \\
& Jones (GA) & 144.26 & 0.97 & 0.99 \\
Georgia Highway 141 & SRC & 297.29 & 0.91 & 0.98 \\
& Jones (GRG) & 98.70 & 0.97 & 0.99 \\
& Jones (GA) & 98.70 & 0.97 & 0.99 \\
\hline
\end{tabular}

Table 4 Performance indices for two sites during validation

\begin{tabular}{llrll}
\hline Station & Method & RMSE & IA & Correlation \\
\hline Littles Ferry Bridge & SRC & 684.01 & 0.88 & 0.95 \\
& Jones (GRG) & 161.09 & 0.97 & 0.99 \\
& Jones (GA) & 161.09 & 0.97 & 0.99 \\
Georgia Highway 141 & SRC & 310.01 & 0.90 & 0.97 \\
& Jones (GRG) & 93.09 & 0.97 & 0.99 \\
& Jones (GA) & 93.09 & 0.97 & 0.99 \\
\hline
\end{tabular}

where $X$ is the observed discharge, $Y$ is the estimated discharge, and $\bar{X}$ is the average discharge.

The results of quantitative analysis during calibration and validation are presented in Tables 3 and 4 respectively. Appraisal of Tables 3 and 4 reveals that the discharge estimated by Jones formula was found to be more accurate than the conventional method of establishing simple rating curves for either sites. The results of qualitative analysis are presented in Figs. 1 and 2 which shows that nonlinear optimization techniques GRG and GA quite satisfactorily mimic the hysteresis effect in the rating curves of the two sites. Further, the spreadsheet-based optimization GRG technique results in as efficient estimation of discharge as genetic algorithm. Application of GRG technique does not require complex parameter tuning or knowledge of programming language which is a major advantage of using GRG over the genetic algorithm.
Fig. 1 Tracing the looped rating curve of Littles Ferry Bridge using GRG
Fig. 2 Tracing the looped rating curve of Georgia Highway 141 using GRG
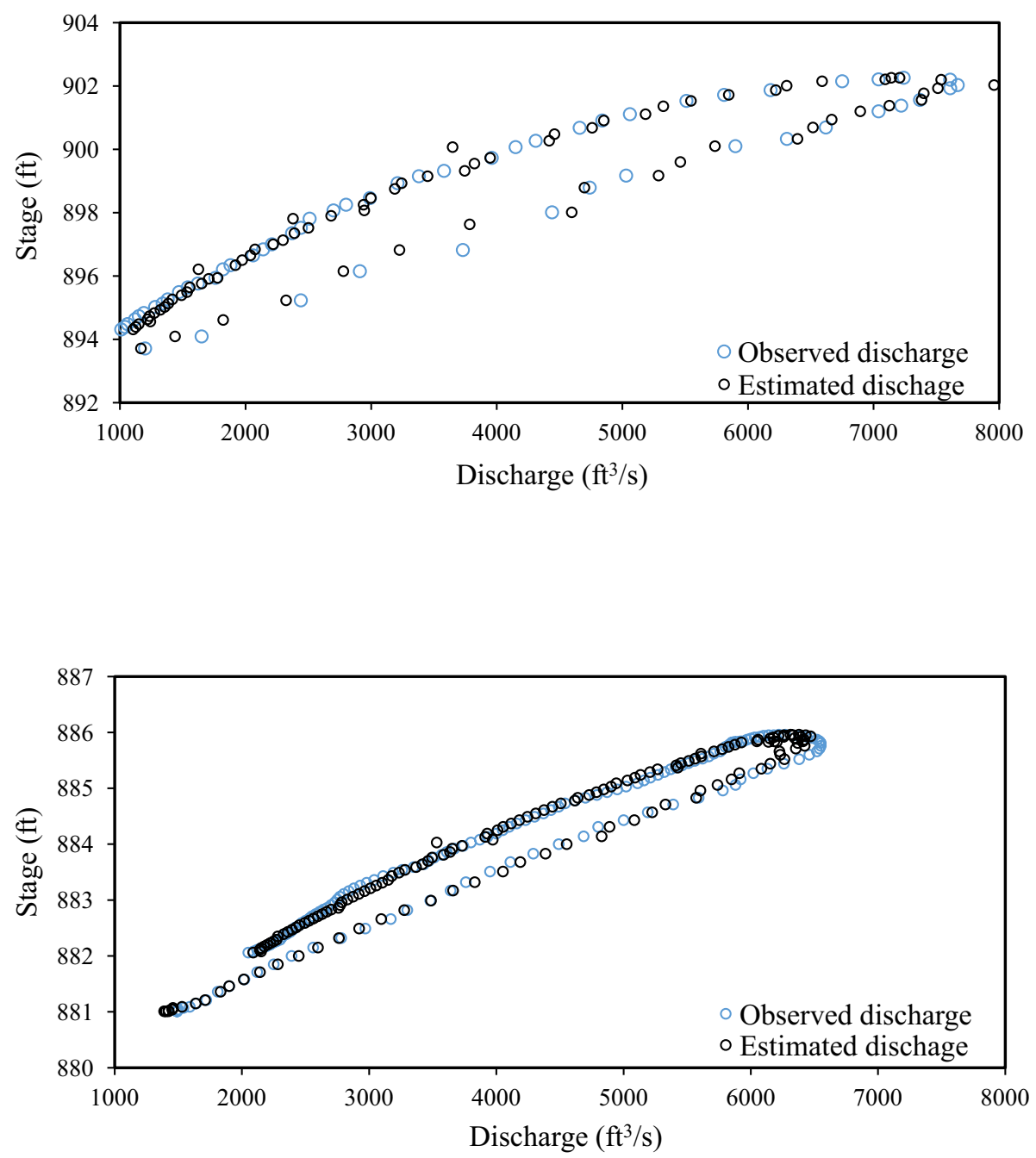


\section{Conclusion}

In this paper, discharge rating curves were established for two sites that were affected by hysteresis. The rating curve was modelled by single-valued simple rating approach and the Jones formula. The discharge estimated by Jones formula was found to be more accurate than the simple rating curve approach. Further, the Jones formula was modelled using GRG technique and GA. It has been found that the spreadsheet-based optimization GRG technique results in as efficient estimation of discharge as genetic algorithm. However, GRG technique is a very simple spreadsheet-based optimization technique which does not require complex parameter tuning and could prove beneficial to the hydrometric departments as most of the hydrometric departments assemble their data on spreadsheets.

Open Access This article is distributed under the terms of the Creative Commons Attribution 4.0 International License (http://creativeco mmons.org/licenses/by/4.0/), which permits unrestricted use, distribution, and reproduction in any medium, provided you give appropriate credit to the original author(s) and the source, provide a link to the Creative Commons license, and indicate if changes were made.

\section{References}

Bhattacharjya RK (2011) Solving groundwater flow inverse problem using spreadsheet solver. J Hydrol Eng 16(5):472-477

Che D, Nangare M, Mays LW (2014) Determination of optimal unit hydrographs and Green-Ampt parameters for watersheds. J Hydrol Eng 19(2):375-383

Faye RE, Cherry RN (1980) Channel and dynamic flow characteristics of the Chattahoochee River, Buford Dam to Georgia Highway 141. US Geological Survey Water Supply Paper-2063

Fread DL (1975) Computation of stage-discharge relationships affected by unsteady flow. Water Resour Bull 11:213-218

Goel A, Pal M (2011) Stage-discharge modelling using support vector machine. IJE Trans A Basics 25(1):1-9

Goldberg DE (1989) Genetic algorithms in search, optimization, and machine learning. Addison-Wesley, Boston

Haupt RL, Haupt SE (2004) Practical genetic algorithms, 2nd edn. Wiley, Hoboken

Herschy RW (1995) Streamflow measurement, 2nd edn. E \& FN Spon, London

Holland JH (1975) Adaptation in natural and artificial systems. University of Michigan Press, Ann Arbor
Jain SK, Chalisgaonkar D (2000) Setting up stage-discharge relations using ANN. J Hydrol Eng 5(4):428-433

Jones BE (1916) A method of correcting river discharge for a changing stage. US Geological Survey Water Supply Paper 375-E

Lasdon LS, Smith S (1992) Solving sparse nonlinear programs using GRG. ORSA J Comput 4(1):2-15

Lasdon LS, Waren AD, Jain A, Ratner M (1978) Design and testing of a generalized reduced gradient code for nonlinear programming. ACM Trans Math Softw 4(1):34-50

Muzzammil M, Alam J, Zakwan M (2015) An optimization technique for estimation of rating curve parameters. In: National symposium on hydrology, New Delhi, India, pp 234-240

Pandey M, Zakwan M, Sharma PK, Ahmad Z (2018) Multiple linear regression and genetic algorithm approaches to predict temporal scour depth near circular pier in non-cohesive sediment ISH. J Hydraul Eng. https://doi.org/10.1080/09715010.2018.1457455

Perumal M, Ranga Raju KG (1999) Approximate convection-diffusion equations. J Hydrol Eng 4:160-164

Perumal M, Shrestha KB, Chaube UC (2004) Reproducing hysteresis in rating curves. J Hydraul Eng 130:870-878

Petersen-Øverleir A (2006) Modelling stage-discharge relationships affected by hysteresis using the Jones formula and nonlinear regression. Hydrol Sci 51(3):365-388

Sudheer KP, Jain SK (2003) Radial basis function neural network for modelling rating curves. J Hydrol Eng 8(3):161-164

Tawfik M, Ibrahim A, Fahmy H (1997) Hysteresis sensitive neural network for modelling rating curves. J Comput Civ Eng 11(3):206-211

Weiss PT, Gulliver JS (2001) What do students need in hydraulic design projects? J Hydraul Eng. https://doi.org/10.1061/ (ASCE)0733-9429(2001)127:12(984)

Westphal J, Thompson D, Stevens G Jr., Strauser C (1999) Stage-discharge relations on the middle Mississippi River. Water Resour Plan Manag 125:48-53

Zakwan M, Muzzammil M (2016) Optimization approach for hydrologic channel routing. Water Energy Int 59(3):66-69

Zakwan M, Muzzammil M, Alam J (2016) Application of spreadsheet to estimate infiltration parameters. Perspect Sci. https://doi. org/10.1016/j.pisc.2016.06.064

Zakwan M, Muzzammil M, Alam J (2017a) Application of data driven techniques in discharge rating curve-an overview. Aquademia Water Environ Technol 1(1):02

Zakwan M, Muzzammil M, Alam J (2017b) Developing stage-discharge relations using optimization techniques. Aquademia Water Environ Technol 1(2):05

Publisher's Note Springer Nature remains neutral with regard to jurisdictional claims in published maps and institutional affiliations. 